work. Thanks to the publicity which was given by NATURE to the needs of these young men, I was able to place a certain number of them in good commercial laboratories, and it is satisfactory to know that in nearly all cases they have justified my opinion of them and are doing well. More than thirty have been placed during the past three years, and are under my supervision still.

The council has recently referred to me a large number of these lads who are shortly leaving its service, and I should be glad to be permitted to make this fact known among readers of Nature, as $\mathbf{I}$ am confident that should any employers desire promising assistants for their laboratories they would be able to obtain satisfactory applicants through this source. Applications should be made to the hon. secretary, Apprenticeship and Skilled Employment Association, 51 Denison House, 296 Vauxhall Bridge Road, S.W.

May I4. G. E. REISS, Hon. Secretary.

\section{The Use of Spectacles with Optical Instruments.}

With reference to the inquiry in Nature of May I (p. 215), the general rule in cases where a person using spectacles wishes to use an optical instrument is, that for telescopes and instruments used for distant objects, use the distance correction; for microscopes and instruments for near work, the near correction should be worn. Care should always be taken to use the centre of the spectacle lens. If no astigmatism is present there is generally sufficient focussing room to enable the observer to dispense with the spectacles. The most comfortable method is to have a cap made for the eyepiece of the instrument with a lens equivalent to that in the spectacle. This should be set as close to the eye-lens as possible, and in cases of astigmatism they should be marked so that the axis may be correctly set. Any good optician will do this at small expense.

HERBERT S. RYLAND

9 Alwyne Square, Canonbury Park, N., May I4.

\section{NATURAL HISTORY AND SPORT. ${ }^{1}$}

(I) $\mathrm{I}^{\mathrm{T}}$ is now six years since the publication of Captain Shelley's great monograph of the birds of Africa was suspended by the illness that overtook and ultimately proved fatal to the author. Fears, however, that the work might remain unfinished were happily allayed by the announcement that Mr. W. L. Sclater had undertaken to carry it on to completion. Several years elapsed before the final arrangement could be made, and it was not until I912 that Mr. Sclater was able to bring out the volume under notice, which deals with the Lanii or drongos and shrikes, and is the second part of the fifth volume. This part is in every way up to the standard of its predecessor, and shows that Captain Shelley could not have committed the task to more competent hands than those of Mr. Sclater, who has a genius for sys-

1 (1) "The Birds of Africa." Comprising all the Species which occur in the Ethiopian Region, By P. E. Shelley. Vol. v., part ii., completed and edited by W. L. Sclater. Pp. viii $+265-502$. (London: H. Sotheran and Co., 1012.) Price 31s. 6 d net.

(2) "The Snakes of South Africa." Their Venom and the Treatment of (2) "The Snakes of South Africa." Their Venom and the Treatment of
Snake Bite. By F. W. Fitzsimons. New edition. Pp. xvi +547. (Cape Snake Bite. By F. W. Fitzsimons New edition. Pp. Xvi +547 . (Cape Cown and Pretoria: $\mathrm{T}$. $\mathrm{M}$.

(3) "The Adventures of an Elephant Hunter." By J. Sutherland. Pp. xix+324. (London: Macmillan and Co., Ltd., rgr2.) Price $7 s .6 d$.

(4) "Baby Birds at Home." By R. Kearton. Pp. xv+128. (London : Cassell and Co., Ltd., 1912.) Price 6s.

No. 2273, VOL. 9I] tematic ornithology. The book would certainly have been improved and its cost not greatly increased by the addition of a few outline figures in the text to illustrate some of the structural characters of the birds; but the eight coloured plates drawn by that competent draughtsman and greatly improved bird-artist Mr. A. Grönvold are excellent. Apart from the systematic descriptions and the useful analytical identification keys, a full account of the known distribution of every species is given, and its habits, where observed, have been duly recorded.

(2) As director of the museum at Port Elizabeth, Mr. F. W. Fitzsimons has had exceptional opportunities of studying the snakes of South Africa, and his volume is the outcome of observations, extending over many years, upon these reptiles both in their native haunts and in captivity; and, thanks to his freedom from the restrictions imposed in some other countries, he has been able to make a long series of experiments upon the venom of the poisonous species. These experiments have shown, amongst other things, that none of the snake-killing mammals and birds of South Africa, like the mongooses, zorillas, hedgehogs, and sccretary birds, is immune against snake venom, as has been stated and is often believed, but that one and all owe their ability to escape from and overcome even such redoubtable antagonists as the puffadder and yellow cobra either to their extreme quickness in warding off or avoiding the stroke or to their protective armature. The experiments have also convinced Mr. Fitzsimons that the antivenene recommended by Dr. Martin and Major Lamb "by no means possesses the high standard of venom-killing power some people claim for it." These are only samples of the interesting matter contained in the volume, which is a medley of varied information, anecdotes relating to habits and field experiences being sandwiched between technical diagnoses of genera species, often taken verbatim from the Britis inguseum catalogue, the whole subject-matter being presented in such a manner as to make a volume both useful to the specialist and readable to the ordinary layman.

(3) The tale of Mr. Sutherland's ten years' adventures as an elephant-hunter in Portuguese and German East Africa is told with a simple charm and ease of style which give his volume a foremost place amongst books of African sport; and the interest of his experiences, some of them unique and most of them exciting, is heightened by the knowledge that he met them single-handed, with only one or two trusted natives to act as trackers and carriers. So vividly are the scenes depicted that on regretfully turning the last page one cannot but echo the sentiment of the author when he writes: "After so many years of a wild, free life, I find it difficult to accommodate myself to the stuffiness and constraint of a modern city; I prefer the forest to the imprisonment of streets, the twinkling stars to lamps, the sigh of the primitive forest to the tramp of thousands of human feet." 
From repeated encounters with African big game of all kinds, Mr. Sutherland concludes that the pursuit of the elephant is beyond doubt the most dangerous. Next come buffaloes and lions, which are about on a par; but it will surprise many of his readers to learn that the risk in shooting rhinoceroses is very small, smaller indeed than that attending the shooting of leopards. The volume is not, however, devoted wholly to sport. It contains much valuable information about the superstitions and social organisation of the natives, as well as harrowing descriptions of intertribal raids, throwing a lurid light on the life of uncivilised man. films had been exhibited there was a short interval, and then the curtain drew up, showing the stage set as an ancient temple, with two rows of columns and a background. This was all decorated in quiet colours such as brown and terracotta, and was only feebly lighted. Two attendants brought on a pair of tables, set them between the back pair of pillars and retired. Then two somewhat ghostly pierrots, dressed in white, appeared to come on the stage, and to play a xylophone duet on instruments on the tables. A gramophone produced the music and kept time with the movement of the players.

The optical effect appears to be produced by a

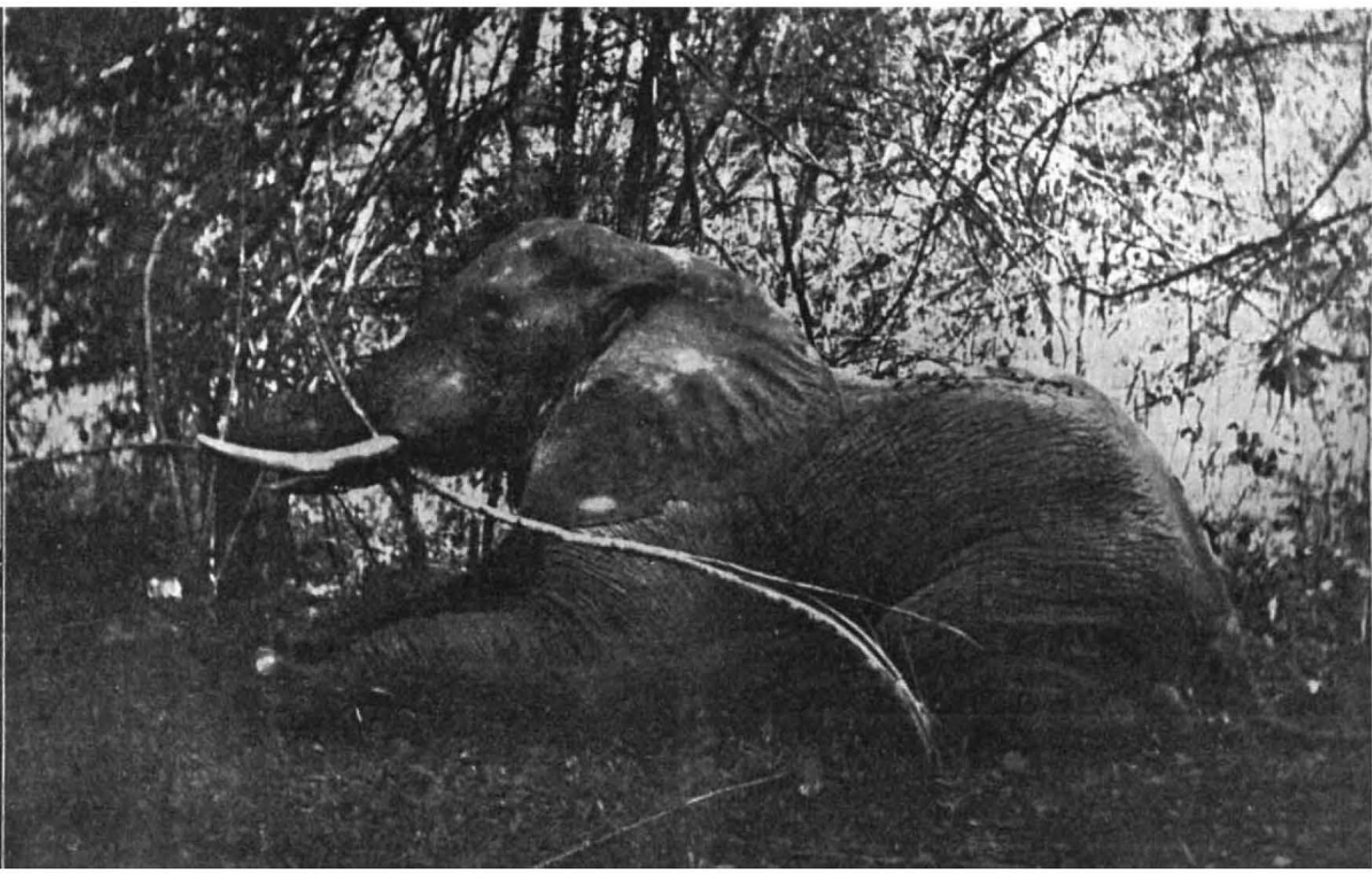

Kom-Kom : the terror of Nagoromenia's kraal. From " The Adventures of an Elephant Hunter.

(4) "Baby Birds at Home" is a book for children. It is written in suitable style, but its chief merit is perhaps the excellence of the photographs with which it is illustrated.

R. I. P.

\section{THE PRODUCTION OF APPARENT RELIEF $B Y$ "KINOPLASTIKON."}

$A T$ the Scala Theatre-the home of "KinemaA color"-there is now being exhibited a new feature, termed "Kinoplastikon," which is advertised as "singing, talking, moving, picture figures without a screen," and has been described in notices in the daily Press as stereoscopic. We visited the theatre recently in order to see this display and discover, if possible, how the stereoscopic effect was produced. We hoped to see some new optical principle illustrated, but in this we were disappointed.

After a number of the now well-known colour NO. 2273 , VOL. 9I] variation of the old "Pepper's Ghost." A huge sheet of plate-glass-it must be 20 to $30 \mathrm{ft}$. square - seems to be set up in a vertical plane, making an angle of $45^{\circ}$ with the front of the stage, so that any brightly lighted object on the left of the stage, as seen from the auditorium, may be seen by the audience by reflection as if it were upon the stage itself. A diagram will make the arrangement clearer. $M N$ is the front of the stage, AB the background. $\mathrm{CD}, \mathrm{EF}, \mathrm{GH}$, the pillars of the temple. GL is the sheet of glass. Then a bright object at $\mathrm{PQ}$ will be seen by the audience at $\mathrm{XYZ}$ as though it were at $\mathrm{P}^{\prime} \mathrm{Q}^{\prime}$.

The figures are apparently projected by an animatograph $\mathrm{O}$ upon a semi-transparent screen at PQ. ${ }^{1}$ Stray light from the lantern coming through the screen could be seen shining

1 In order to avoid the great length from $O$ to the centre of the stage, it is probable that the lantern is placed to shine down from above, or up from below, or even forwards:from $\mathrm{O}^{\prime}$, a silvered mirror reflecting the light into the required direction 